\title{
Article \\ Characterization of Atypical Pheochromocytomas with Correlative MRI and Planar/Hybrid Radionuclide Imaging: A Preliminary Study
}

\author{
Roberta Galatola ${ }^{1, *}$, Ludovica Attanasio ${ }^{1}$, Valeria Romeo ${ }^{1}$, Ciro Mainolfi ${ }^{1}$, Michele Klain ${ }^{1}$, Chiara Simeoli ${ }^{2}$, \\ Roberta Modica ${ }^{2}$ (D), Elia Guadagno ${ }^{1}$, Giovanni Aprea ${ }^{3}$, Luca Basso ${ }^{4}$, Emanuele Nicolai ${ }^{4}$, Marco Salvatore ${ }^{4}$ \\ and Simone Maurea ${ }^{1} \mathbb{D}$
}

1 Department of Advanced Biomedical Sciences, University of Naples “Federico II", 80131 Naples, Italy; ludoattanap@gmail.com (L.A.); valeria.romeo@unina.it (V.R.); c.mainolfi@libero.it (C.M.); michele.klain@unina.it (M.K.); eliaguadagno84@gmail.com (E.G.); maurea@unina.it (S.M.)

2 Department of Clinical Medicine and Surgery, Division of Endocrinology, University of Naples "Federico II", 80131 Naples, Italy; simeolichiara@gmail.com (C.S.); robertamodica@libero.it (R.M.)

3 Department of General and Mini-Invasive Surgery, University of Naples “Federico II", 80131 Naples, Italy; giovanni.aprea@unina.it

4 IRCCS SDN, 80143 Naples, Italy; luca.basso@synlab.it (L.B.); emanuele.nicolai@synlab.it (E.N.); marcosalvatore2.segreteria@gmail.com (M.S.)

Citation: Galatola, R.; Attanasio, L.; Romeo, V.; Mainolfi, C.; Klain, M.; Simeoli, C.; Modica, R.; Guadagno, E.; Aprea, G.; Basso, L.; et al.

Characterization of Atypical

Pheochromocytomas with Correlative MRI and Planar/Hybrid

Radionuclide Imaging: A Preliminary Study. Appl. Sci. 2021, 11, 9666.

https://doi.org/10.3390/app11209666

Academic Editor: Przemysław M. Płonka

Received: 27 July 2021

Accepted: 14 October 2021

Published: 16 October 202

Publisher's Note: MDPI stays neutral with regard to jurisdictional claims in published maps and institutional affiliations.

Copyright: (c) 2021 by the authors. Licensee MDPI, Basel, Switzerland. This article is an open access article distributed under the terms and conditions of the Creative Commons Attribution (CC BY) license (https:// creativecommons.org/licenses/by/ $4.0 /)$
* Correspondence: galatolaroberta@gmail.com; Tel.: +39-0817-463-560; Fax: +39-0815-457-081

Abstract: Pheochromocytomas may show atypical imaging findings leading to diagnostic pitfalls. We correlated the results of magnetic resonance imaging (MRI) with those of radionuclide studies in patients with pheochromocytomas. T2-weighted (-w), T1-w chemical-shift and T1-w dynamic contrast enhanced (DCE) MRI sequences were evaluated to assess tumor structure. ${ }^{131}$ Iodine metaiodobenzylguanidine (MIBG) scintigraphy, ${ }^{18}$ fluoro (F) deoxyglucose (FDG) positron emission tomography/computed tomography (PET/CT) or FDG PET/MRI were evaluated for direct comparison. Of a total of 80 adrenal lesions in 73 patients, 20 in 18 patients were pheochromocytomas. More than half $(55 \%)$ of the pheochromocytomas $(n=11)$ had the typical increased signal intensity on $T 2-w$ and T1-w DCE, while the remaining $(n=9)$ lesions showed atypical findings; of these nine latter atypical lesions, seven (35\%) were cystic (two totally, three predominantly and two partially) and two $(10 \%)$ were hemorrhagic on MRI. In these atypical lesions, MIBG scintigraphy $(\mathrm{n}=5)$, FDG PET/CT $(n=6)$ or FDG PET/MRI $(n=2)$ showed inhomogeneous tracer uptake in the residual viable tissue providing tumor characterization; however, one predominantly cystic pheochromocytoma showed false negative MIBG scan. Our preliminary results show that cystic degeneration may be frequent in pheochromocytoma being so marked that only a thin rim of viable cells may residue to disclose the true nature of the tumor. MRI findings together with those of correlative planar/hybrid radionuclide images are helpful to characterize these atypical pheochromocytomas. In particular, tumor accumulation of MIBG and/or FDG is able to classify these lesions as not simple cysts; in detail, the presence of partial MIBG uptake allows the diagnosis of pheochromocytomas, while the presence of partial FDG uptake generically reflects the presence of viable solid tissue of such cystic tumors.

Keywords: pheochromocytoma; atypical; cystic; MRI; radionuclide planar/hybrid imaging

\section{Introduction}

Pheochromocytomas (pheos) are rare catecholamine-secreting neoplastic lesions arising from chromaffin cells of the adrenal medulla [1]. Usually, these tumors are clinically symptomatic for their increased catecholamine secretion and, hence, imaging detection is required for treatment planning [2,3]. For this purpose, magnetic resonance imaging $(\mathrm{MRI})$ as well as computed tomography (CT) are the first line imaging modalities used for 
such patients. Usually, on MRI pheos appear as solid round masses with homogeneous increased signal intensity on T2-weighted (-WI) and low signal intensity on T1-WI images with avid enhancing and poor wash-out after intravenous contrast medium administration on T1-WI dynamic contrast enhanced (DCE) sequence [2]. Moreover, on radionuclide imaging these tumors show increased focal tracer uptake using radiolabeled agents such as metaiodobenzylguanidine (MIBG), dihydroxyphenylalanine (DOPA), fluorodeoxyglucose (FDG) and somatostatin analogs [4-10]; in particular, these radiopharmaceuticals target specific functional and molecular tumor pathways reflecting catecholamine synthesis, glucose metabolism and somatostatin receptors (SR) expression, respectively. However, pheos may show atypical lesion characteristics when undergoing different degrees of tissue degeneration such as necrosis, hemorrhage, calcification, cystic or intracellular lipid changes, making their clinical and imaging behaviors unpredictable as well as mimicking other adrenal tumors [2,8-14]. Of note, Jacques et al. [11] reported increased MRI signal intensity heterogeneity correlating pathologically with high amounts of haemorrhage, necrosis and fibrosis; of note, cystic degeneration may be so marked that only a thin rim of viable cells may remain to disclose the true nature of lesion [12]. Raja et al. [15] described several atypical patterns of pheos consisting of cystic change, hemorrhage, intense contrast enhancement, calcifications and intracellular lipid component. Similarly, MIBG scintigraphy has been described to be useful in atypical pheo showing increased tracer uptake only in the solid viable peripheral portion of tumors [15-17]. For these reasons, the discovery of these atypical pheos is not easy in clinical practice, often resulting in delayed diagnostic and therapeutic management with clinical consequences because of excessive catecholamine production $[1,18]$. To further complicate the clinical scenario, hereditary pheos may show false negative radionuclide MIBG images, getting the diagnosis even more difficult [3].

The aim of this retrospective study was to assess the correlative images using MRI and radionuclide techniques in atypical pheos in order to describe imaging features of such tumors which may reflect morpho-functional lesion features and thus may help in tumor diagnosis and characterization.

\section{Materials and Methods}

\subsection{Study Population}

This retrospective study was approved by our Institutional Review Board (protocol code 10/17) and informed consent waived. Our institutional archive was searched to identify abdominal MRI scans of patients with adrenal lesion between 2008 and 2020. Patients with pheos were extrapolated and included in the final study population using the following criteria: (1) tumors proven by histopathology; (2) MRI study including T2-WI, T1-WI, chemical-shift (CS), T1-w DCE sequences; (3) planar and/or hybrid radionuclide studies such as ${ }^{131}$ I MIBG scintigraphy, ${ }^{18}$ F FDG PET/CT and/or PET/MR); (4) clinical symptoms related to adrenal medullary hyperfunction as documented by plasma and urinary hormones levels such as catecholamines and/or their metabolites. Patients were classified as showing hypersecreting or non-hypersecreting tumor lesions.

\subsection{MRI Protocol}

MRI studies were acquired using a 3T machine (Magnetom Trio, Siemens, Erlangen, Germany) equipped with a surface-body coil. The imaging protocol consisted of the following non-contrast sequences: CS T1-WI VIBE (TR/TE = 4.04/1.26 ms; TR/TE = 4.04/2.59; slice thickness $=3 \mathrm{~mm}$; no gap) in- and out-of-phase on axial planes, T2-WI HASTE $(\mathrm{TR} / \mathrm{TE}=2000 / 90 \mathrm{~ms}$; slice thickness $=3 \mathrm{~mm}$; gap $=0.6 \mathrm{~mm})$ with fat suppression on axial planes, T2-WI HASTE $(\mathrm{TR} / \mathrm{TE}=2000 / 90 \mathrm{~ms}$; slice thickness $=3 \mathrm{~mm}$; gap $=0.6 \mathrm{~mm}$ ) on axial and coronal planes, Dynamic contrast enhanced $(0.1 \mathrm{mmol} / \mathrm{kg}$ Gd-DTPA Magnevist, Bayer Pharma, Berlin, Germany) T1-WI VIBE 3D (TR/TE = 3.3/1.1 ms; slice thickness = 2 mm; no gap) were obtained before contrast administration and in arterial (30 s), portal (60 s) and delayed phases (5 min and $10 \mathrm{~min}$ ) on axial planes after injection. 


\subsection{Radionuclide Studies}

\subsubsection{Planar Iodine-131 MIBG Scintigraphy}

Before intravenous tracer injection, thyroid iodine accumulation was blocked with a saturated solution of potassium iodide ( $200 \mathrm{mg}$ /day per os, 1 day before tracer injection, subsequently for at least 5 days). Medical therapy potentially interfering with MIBG uptake was discontinued as recommended [7]. Iodine-131 MIBG (37 MBq; GE Healthcare, Braunschweig, Germany) was used. Anterior and posterior planar total-body (TB) scans as well as anterior and posterior abdominal spot views were acquired 24,48 and $72 \mathrm{~h}$ after tracer administration using a large-field-of-view gamma camera (Skylight; Philips Healthcare, Best, The Netherlands) with a high-energy collimator and a $20 \%$ window centered at $364 \mathrm{keV}$. In detail, anterior and posterior TB images were obtained with a table advancement speed of $4 \mathrm{~cm} / \mathrm{min}$, while anterior and posterior abdominal spot views were recorded in pre-set count acquisition for at least 150.000 counts for each scan.

\subsection{2. ${ }^{18}$ F-FDG Hybrid Imaging}

${ }^{18} \mathrm{~F}$-FDG PET/CT studies were acquired using a Gemini TF 64 scanner (Philips Healthcare). All patients fasted for at least $6 \mathrm{~h}$ prior to imaging and with blood glucose levels $<180 \mathrm{mg} / \mathrm{dL}$ at the time of tracer injection. PET scans were acquired in 3-D mode starting $60 \mathrm{~min}$ after ${ }^{18} \mathrm{~F}$-FDG administration (activity range $200-300 \mathrm{MBq}$, according to body weight). A low- $(70 \mathrm{mAs})$ and high-dose $(230 \mathrm{mAs}) \mathrm{CT}$ scans (rotation time $1.5 \mathrm{~s}$, collimation $16 \AA \sim 0.625$ ) were obtained for attenuation correction of emission data. The sinogram of emission data was reconstructed using the 3-D row action maximum likelihood algorithm, taking into account attenuation, detector efficiency, scatter and random coincidence corrections. Attenuation correction was obtained using CT images. CT and PET images were compared and fused into transaxial, coronal, and sagittal images.

\subsection{3. ${ }^{18}$ F-FDG PET/MRI}

${ }^{18} \mathrm{~F}$-FDG PET/MRI was performed on the Biograph mMR system (Siemens Healthcare, Erlangen, Germany). A dose of $401 \pm 35 \mathrm{MBq}$ of ${ }^{18} \mathrm{~F}$-FDG was injected depending on patient's body weight; after an uptake period $80 \pm 16 \mathrm{~min}$, patients underwent imaging acquisition. This device consists of a 3T MRI scanner featuring high-performance gradient systems $(45 \mathrm{mT} / \mathrm{m})$ and a slew rate of $200 \mathrm{~T} / \mathrm{m} / \mathrm{s}$. A fully functional PET system, equipped with the avalanche photodiode technology, is embedded into the magnetic resonance gantry. Bed position was established in order to get a full coverage of the superior abdomen. After a correct positioning had been ensured, the simultaneous PET/MRI scanning started. First, a coronal 2-point Dixon 3-dimensional volumetric interpolated breath-hold T1-WI MRI sequence was obtained and used for the generation of attenuation maps and for anatomic allocation of the PET results. The software of the MRI scanner automatically generated four different images: T1-WI in-phase, T1-WI out-of-phase, water-only and fat-only. For attenuation correction of the PET data from the PET/MR scanner, attenuation maps generated on the basis of the Dixon MRI sequence were applied. Axial and coronal STIR $(T R / T E / T I=4220 / 61 / 220 \mathrm{~ms})$. Perfusion $(\mathrm{DCE})$ studies were acquired after the intravenous administration of paramagnetic contrast agent $(0.2 \mathrm{~mL} / \mathrm{kg}$, Magnevist, Bayer, Berlin, Germany), using a T1-WI FS Vibe_transaxial_dynamic (TR/TE $=5.37 / 1.78 \mathrm{~ms})$ sequence with 50 measurements. 


\subsection{Imaging Analysis}

MRI studies were evaluated by two radiologists expert in abdominal imaging working in consensus to detect adrenal tumors as well as to describe lesion structure characteristics according to MRI images. They were blinded to clinical and histopathological data. MRI were anonymized and evaluated in random order. In particular, all sequences of the same MRI study were contextually visualized in order to assess tumor lesion signal intensity on T2-WI, T1-WI, T1-WI CS, and T1-WI DCE images. Pheos were divided into two groups based on their typical or atypical appearance on MRI, as previously described [9]. In particular, pheos were classified as typical if they showed homogeneous solid structure as showing low T1-WI signal intensity, high T2-w signal intensity, no signal drop on T1-WI out-of-phase CS sequence, avid enhancing and poor wash-out on T1-WI FS DCE sequence. Conversely, pheos were defined atypical if they did not match MRI typical features as showing cystic and hemorrhagic changes; in particular, cystic changes were classified as total, predominant or partial [15]. Radionuclide studies were evaluated according to the availability of nuclear scans assessing the presence of abnormal (focal, homogeneous, heterogeneous, peripheral) tracer (MIBG and/or FDG) uptake in adrenal tumors; for FDG uptake standardized uptake value (SUV) was also measured. Simple descriptive statistics (mean, standard deviation, percentage) were used to show numeric data; calculations were performed with Excel 2020 (Microsoft, Washington, WA, USA)

\section{Results}

\subsection{Study Population}

Overall, a total of 73 patients with 80 adrenal tumors were retrospectively identified. Of these patients, 18 (25\%) patients (10 women and eight men, median age 53 years, age range 25-82 years) with pheos were extrapolated representing the final study population. In particular, all patients with pheos had one tumor lesion, except in one case who had three lesions for a total of 20 tumor lesions. Histopathology confirmation was available in 16 patients, while the remaining two patients refused surgical treatment; for these latter cases the results of radionuclide studies (MIBG) were considered to support and confirm tumor diagnosis. Tables 1 and 2 show clinical, laboratory and imaging findings in patients with typical $(n=9)$ and atypical $(n=9)$ pheos, respectively. Genetic testing was performed only in two patients because of the young age (25 years old) and the recurrence and bilaterality of tumor after surgery, respectively; in particular, the first patient had a MEN 2A syndrome while the second one had a Von Hipple Lindau gene mutation.

\subsection{Correlative MRI and Radionuclide Imaging \\ 3.2.1. Typical Pheos}

Of the total 20 pheos included in our series, 11 tumor lesions were classified as typical because of their classical solid hyper-vascular mass appearance on MRI (Table 1). In particular, three lesions showed the typical bright signal intensity on T2-WI images, while the remaining eight lesions showed an inhomogeneous high signal intensity on T2-WI images. All lesions showed no signal drop on T1-WI out-of-phase CS sequence. All lesions showed low signal intensity on T1-WI and were avidly enhancing on T1-w FS images after contrast administration. The corresponding results of radionuclide studies in such patients are illustrated in Table 1. In particular, MIBG scans were available in 6 patients in which 8 tumor lesions were detected; of note, the majority $(75 \%)$ of lesions $(n=6)$ had focal increased tracer uptake, while the remaining two lesions were falsely negative. ${ }^{18} \mathrm{~F}-\mathrm{FDG}$ $\mathrm{PET} / \mathrm{CT}$ was performed only in two patients with a single large lesion with heterogeneous increased tracer uptake showing SUV max of 3.7 and 3.0, respectively. 
Table 1. Clinical and imaging characteristics of typical MRI pheochromocytomas.

\begin{tabular}{|c|c|c|c|c|c|c|c|c|c|}
\hline \multicolumn{3}{|c|}{ Patient } & \multirow{2}{*}{$\begin{array}{l}\text { Clinical } \\
\text { Symptoms }\end{array}$} & \multirow{2}{*}{$\begin{array}{l}\text { Adrenal } \\
\text { Medullary } \\
\text { Secretion }\end{array}$} & \multirow{2}{*}{$\begin{array}{c}\text { MRI } \\
\text { Structure }^{1}\end{array}$} & \multirow{2}{*}{$\begin{array}{l}\text { Tumor } \\
\text { Size } \\
(\mathrm{mm})^{2}\end{array}$} & \multirow[b]{2}{*}{ Histology } & \multicolumn{2}{|c|}{ Nuclear Imaging } \\
\hline$\#$ & Sex & $\begin{array}{c}\text { Age } \\
\text { (years) }\end{array}$ & & & & & & MIBG & FDG \\
\hline$\# 1$ & $\mathrm{~F}$ & 82 & Hypertension & Hyper-Secreting & Solid & 23 & + & + & n.a. \\
\hline \#2 & M & 72 & Hypertension & Hyper-secreting & $\begin{array}{c}\text { Solid } \\
\text { heterogeneous }\end{array}$ & 38 & + & n.a. ${ }^{\circ}$ & n.a. ${ }^{\circ}$ \\
\hline \#3 & M & 25 & None & $\begin{array}{c}\text { Non- } \\
\text { hypersecreting }\end{array}$ & Solid & 80 & + & n.a. & + \\
\hline$\# 4$ & $\mathrm{~F}$ & 73 & None & $\begin{array}{c}\text { Non- } \\
\text { hypersecreting }\end{array}$ & Solid & 15 & + & - & n.a. \\
\hline \#5 & $\mathrm{F}$ & 32 & $\begin{array}{c}\text { Abdominal } \\
\text { pain; } \\
\text { hypertension }\end{array}$ & Hyper-secreting & Solid & 48 & + & n.a. ^ & n.a. ^ \\
\hline$\# 6$ & M & 56 & None & Hyper-secreting & Solid & 50 & + & + & + \\
\hline \#7 & M & 58 & Hypertension & Hyper-secreting & $\begin{array}{c}\text { Solid } \\
\text { heterogeneous }\end{array}$ & 29 & + & - & n.a. \\
\hline $\begin{array}{l}\# 8 \\
\mathrm{a} \\
\mathrm{b} \\
\mathrm{c}\end{array}$ & M & 42 & None & $\begin{array}{c}\text { Non- } \\
\text { hypersecreting }\end{array}$ & $\begin{array}{l}\text { Solid } \\
\text { Solid } \\
\text { Solid }\end{array}$ & $\begin{array}{c}9 \\
20 \\
50\end{array}$ & * & $\begin{array}{l}+ \\
+ \\
+\end{array}$ & n.a. \\
\hline \#9 & $\mathrm{F}$ & 57 & None & $\begin{array}{c}\text { Non- } \\
\text { hypersecreting }\end{array}$ & $\begin{array}{c}\text { Solid } \\
\text { heterogeneous }\end{array}$ & 30 & n.a. $\S$ & + & n.a. \\
\hline
\end{tabular}

${ }^{1}$ Specific MRI features are described in detail in "material and methods" paragraphs. ${ }^{2}$ Size was measured in term of maximum diameter on axial images. $+=$ abnormal tracer uptake. n.a.: not available. ${ }^{\circ}$ The patient refused radionuclide studies. $-=$ normal tracer uptake. ${ }^{\wedge}$ Nuclear Imaging studies were not available since the female patient was pregnant. ${ }^{*}$ Relapse of previous proven pheochromocytomas.

$\S$ The patient refused surgery since she was asymptomatic.

\subsubsection{Atypical Pheos}

Conversely, the other nine pheos were classified as atypical because they did not show the MRI features observed in typical pheos (Table 2). In this group, two lesions appeared as solid masses showing heterogeneous high signal intensity on T2-WI images with intermingled areas of high signal intensity on T1-WI images, suggesting hemorrhagic degeneration; they were heterogenous enhancing on T1-WI FS images after contrast administration; two lesions appeared as rounded totally cystic lesion with a fluid-fluid level surrounded by a thin rim of peripheric enhanced tissue; three lesions showed predominantly cystic signal intensity with residual enhanced solid tissue in peripherical borders; finally, the remaining two lesions appeared as rounded partially cystic lesions with contextual areas of solid tissue; the signal intensity was heterogeneous on DCE images. All atypical pheos showed no signal drop on T1-WI out-of-phase CS sequence. Imaging examples of totally or partially cystic atypical pheos are shown in Figures 1 and 2, respectively. The corresponding results of radionuclide studies in patients with atypical pheos are illustrated in Table 2. 
Table 2. Clinical and imaging characteristics of atypical MRI pheochromocytomas.

\begin{tabular}{|c|c|c|c|c|c|c|c|c|c|}
\hline \multicolumn{3}{|c|}{ Patient } & \multirow{2}{*}{$\begin{array}{c}\text { Clinical } \\
\text { Symptoms }\end{array}$} & \multirow{2}{*}{$\begin{array}{l}\text { Adrenal } \\
\text { Medullary } \\
\text { Secretion }\end{array}$} & \multirow{2}{*}{$\begin{array}{c}\text { MRI } \\
\text { Structure }^{1}\end{array}$} & \multirow{2}{*}{$\begin{array}{c}\text { Tumor } \\
\text { Size } \\
(\mathrm{mm})^{2}\end{array}$} & \multirow{2}{*}{ Histology } & \multicolumn{2}{|c|}{ Nuclear Imaging } \\
\hline$\#$ & Sex & $\begin{array}{c}\text { Age } \\
\text { (years) }\end{array}$ & & & & & & MIBG & FDG * \\
\hline$\# 1$ & M & 67 & Hypertension & $\begin{array}{c}\text { Non- } \\
\text { hypersecreting }\end{array}$ & $\begin{array}{l}\text { Hemorrhagic } \\
\text { degeneration }\end{array}$ & 25 & + & + & + \\
\hline \#2 & $\mathrm{F}$ & 54 & None & $\begin{array}{c}\text { Non- } \\
\text { hypersecreting }\end{array}$ & $\begin{array}{l}\text { Predominantly } \\
\text { cystic }\end{array}$ & 44 & + & + & n.a. \\
\hline \#3 & M & 34 & $\begin{array}{c}\text { Recurrent } \\
\text { headache, night } \\
\text { sweats; weight } \\
\text { loss; } \\
\text { hypertension }\end{array}$ & Hyper-secreting & $\begin{array}{l}\text { Predominantly } \\
\text { cystic }\end{array}$ & 57 & + & - & + \\
\hline$\# 4$ & $\mathrm{~F}$ & 41 & None & Hyper-secreting & Totally Cystic & 50 & + & n.a. & + \\
\hline$\# 5$ & $\mathrm{~F}$ & 72 & Hypertension & Hyper-secreting & Totally Cystic & 70 & + & + & + \\
\hline \#6 & $\mathrm{F}$ & 61 & None & $\begin{array}{c}\text { Non- } \\
\text { hypersecreting }\end{array}$ & $\begin{array}{l}\text { Hemorrhagic } \\
\text { degeneration }\end{array}$ & 38 & + & n.a. & + \\
\hline \#7 & M & 57 & Hypertension & Hyper-secreting & $\begin{array}{l}\text { Predominantly } \\
\text { cystic }\end{array}$ & 47 & + & n.a. & + \\
\hline$\# 8$ & $\mathrm{~F}$ & 42 & Tachycardia & Hyper-secreting & Partially cystic & 50 & + & + & + \\
\hline$\# 9$ & $\mathrm{~F}$ & 30 & Hypertension & Hyper-secreting & Partially cystic & 40 & + & n.a. & + \\
\hline
\end{tabular}

${ }^{1}$ Specific MRI features are described in detail in "material and methods" paragraphs. ${ }^{2}$ Size was recorder in term of maximum diameter on axial images. * in patients \#4 and \#8 FDG studies were acquired using PET/MRI. + = abnormal tracer uptake. n.a.: not available. $-=$ normal tracer uptake.

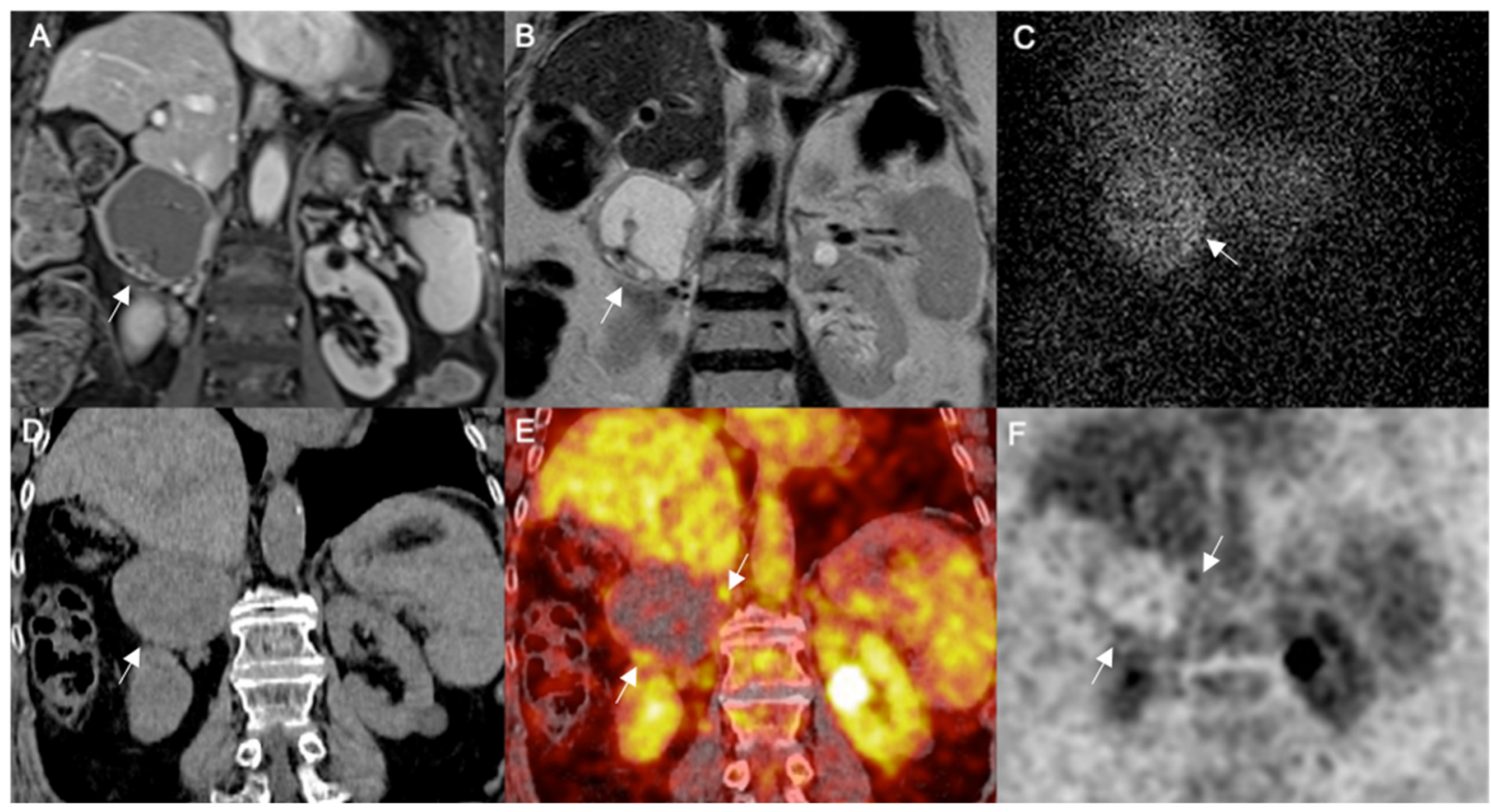

Figure 1. Large right adrenal totally cystic pheochromocytoma. MRI coronal images represented by T1-WI FS enhanced (A) and T2-WI (B) show a cystic large adrenal mass with capsular contrast enhancement measuring $7 \mathrm{~cm}$ (arrows). Planar adrenal scintigraphy with ${ }^{131}$ I MIBG in anterior view at $48 \mathrm{~h}$ after tracer injection (C) shows inhomogeneous tracer uptake in the adrenal lesion, more evident in the capsular rim thickened on the left side (arrow). ${ }^{18}$ FDG PET-CT coronal image shows a hypodense large adrenal mass with regular margins (arrow) on unenhanced CT scan (D); hybrid fused PET-CT image (E) shows faint increased irregular FDG uptake only in the peripheral rim of the lesion as also confirmed by the extracted FDG image (F) (double arrows). 


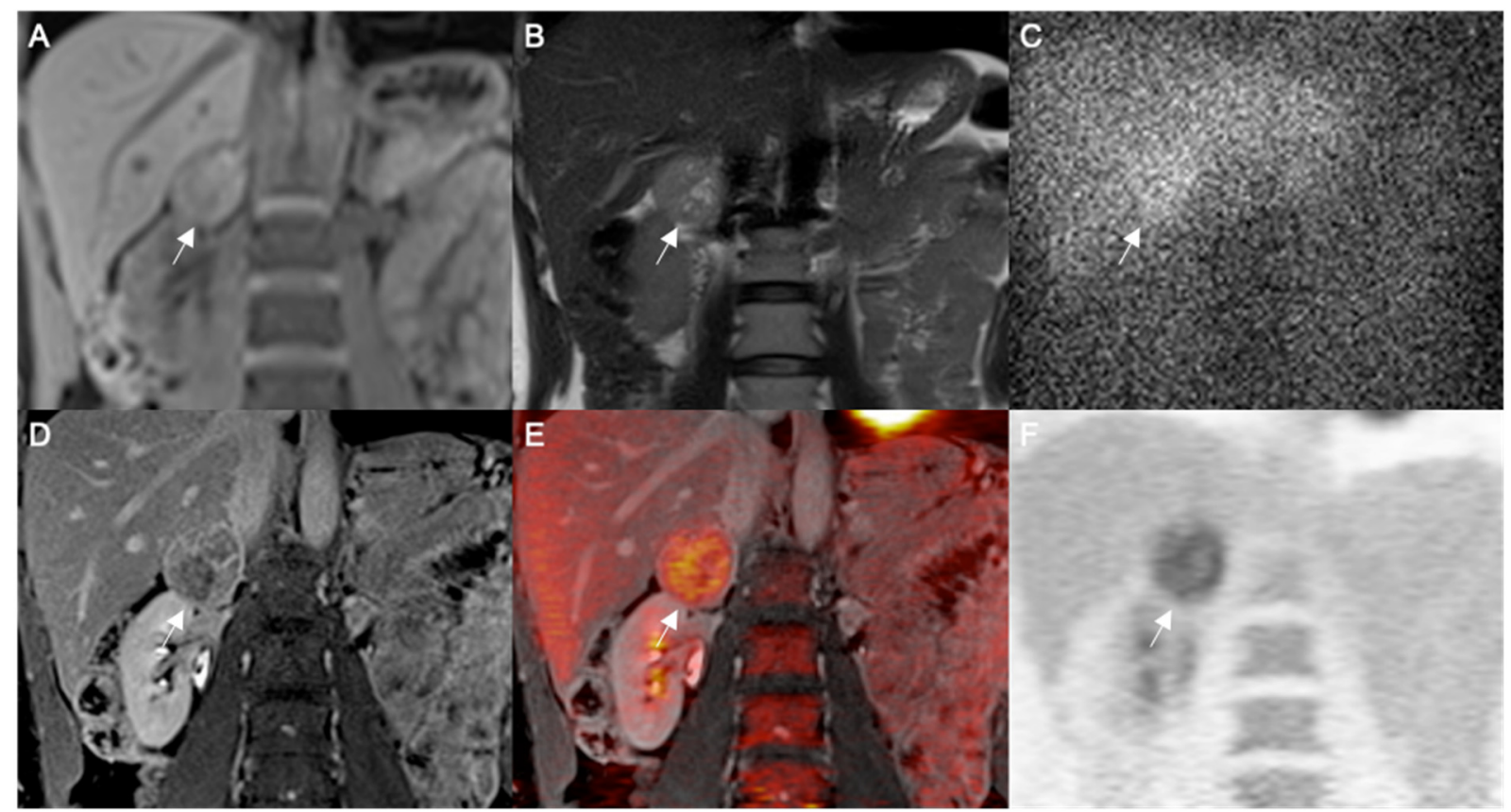

Figure 2. Right adrenal partially cystic pheochromocytoma. MR coronal images represented by T1-WI (A) and T2-WI (B) show a partially cystic adrenal mass measuring $5 \mathrm{~cm}$ (arrows). Planar adrenal scintigraphy with ${ }^{131} \mathrm{I}$ MIBG in anterior view at $48 \mathrm{~h}$ after tracer injection $(\mathrm{C})$ shows inhomogeneous tracer uptake in the adrenal lesion (arrow). ${ }^{18}$ FDG PET-MRI coronal image shows a heterogeneously hypointense adrenal mass with regular margins (arrow) on enhanced MRI scan (D); hybrid fused PET-MRI image (E) shows heterogeneous abnormal FDG accumulation in the residual solid component of the adrenal mass (arrows), as also confirmed by the extracted FDG image (F).

In particular, MIBG scans were available in five tumors of which four $(80 \%)$ showed abnormal heterogeneous residual tracer uptake (one totally cystic, one predominantly cystic, one partially cystic and one hemorrhagic), while the last one (predominantly cystic) was falsely negative. ${ }^{18} \mathrm{~F}$-FDG PET/CT was performed in six lesions showing tracer uptake only by the residual solid component or peripheral rim of tumor structure, of which one was totally cystic, two predominantly cystic, one partially cystic and two hemorrhagic.

${ }^{18} \mathrm{~F}$-FDG PET/MR was performed in two lesions showing tracer uptake only by the residual solid component or peripheral rim of tumor structure, of which one was totally and one was partially cystic. The results of hybrid ${ }^{18} \mathrm{~F}-\mathrm{FDG}$ imaging showed heterogeneous tracer uptake in the $100 \%$ of tumor lesions $(n=8)$. In these lesions the measurement of SUV max ranged from 1.6 to 10.5 . Imaging examples of totally or partially cystic pheos are shown in Figures 1 and 2, respectively.

\section{Discussion}

Pheos consist of catecholamine-secreting tumor lesions originating from chromaffin cells in the medullary of adrenals $[18,19]$. Tumor diagnosis depends on imaging detection of an adrenal lesion associated with specific clinical symptoms and laboratory demonstration of increased catecholamine production. In the majority of cases, pheos show typical imaging features as solid, hyper-vascular tumors with increased CT density (>10 UH) and significantly high signal intensity on T2-WI MRI [2,14,20]; furthermore, pheos on nuclear imaging studies are mainly reflected by increased tracer uptake using MIBG and / or ${ }^{18} \mathrm{~F}$-dihydroxyphenylalanine (DOPA) as well as also by ${ }^{18} \mathrm{~F}$ FDG [4-7]. Of note, the role of ${ }^{18} \mathrm{~F}$ FDG is limited in pheos since this radiocompound is unspecific for this tumor type; however, ${ }^{18} \mathrm{~F}$ FDG is able to reflect the residual viable/solid tissue in case of lesion degeneration; in fact, pheos usually undergo different types of lesion degeneration such as necrosis, calcification, fibrosis, cystic or intracellular lipid changes, misleading the accurate 
tumor diagnosis and thus the epithet of "an imaging chameleon" has been formulated in its atypical appearances [2]. Furthermore, SR may be overexpressed in pheo so that this feature may be detected with SR nuclear imaging; originally, indium-111 pentetreotide has been used to image SR positive pheos [8,9]; recently, gallium-68 DOTA peptides, as DOTATOC, DOTATATE and DOTANOC, have been proposed as PET/CT radiotracer to detect SR in pheo showing high diagnostic accuracy [10].

However, atypical pheos have been described with different imaging characteristics compared to the typical appearance of such tumor [2,11-19]. In particular, these atypical lesions may be misdiagnosed since occur more frequently in asymptomatic patients without biochemical abnormalities compared to typical solid tumors [18]. MRI signal intensity heterogeneity has been reported reflecting tumor changes in atypical pheos [11]; of note, tumor cystic degeneration has been classified as total, predominant or partial with different imaging findings [15]. In addition, MIBG scintigraphy has been described to be useful in this type of pheo in some case reports showing increased tracer uptake confined only to the solid viable peripheral portion of tumors [15-17]. Similarly, MIBG uptake has been reported in a case of cystic malignant pheo with liver infiltration demonstrating also the efficacy of iodine-131 MIBG therapy in such patient who had excellent clinical and imaging responses to the radioactive treatment [21].

In the present preliminary study, we investigated the role of planar/hybrid nuclear imaging using radiolabeled MIBG and/or FDG agents to characterize atypical pheos systematically correlating radionuclide and MRI images. In our experience the incidence of pheos in a series of adrenal tumors observed in a period of twelve years was $25 \%$ ( $n=18 / 73$ patients); in particular, in such cases a total of 20 pheos were summed since three tumor lesions were detected in the same patient. An interesting imaging finding was that almost the half of pheos consisted of atypical tumor lesions on the basis of MRI appearances. In detail, we observed 11 solid tumors classified as typical, while the other nine tumors showed unusual MRI features and were classified as atypical. The majority (73\%) of typical pheos $(8 / 11)$ showed a more or less homogeneous hyperintensity to the spleen on T2-WI images, while the remaining three lesions showed the bright signal intensity, isointense to the cerebrospinal fluid (CSF), on T2-WI images confirming the low occurrence (27\%) of the CSF lightbulb bright signal intensity as previously reported in literature $[11,15,22]$. All the typical pheos showed no signal loss on T1-WI out-of-phase CS sequence and significant contrast enhancement on T1-WI FS post-contrast DCE sequence. Conversely, the majority $(78 \%)$ of atypical pheos (7/9) were cystic suggesting that cystic changes represent the most frequent tissue degeneration in such tumors; of note, five of these tumors were totally or predominantly cystic surrounded by residual viable tissue in peripherical borders or the remnant solid component, respectively; only two lesions appeared as partially cystic with contextual areas of solid tissue. The remaining two atypical pheos showed areas of high signal intensity on T1-WI images suggesting hemorrhagic degeneration. All atypical pheos showed no signal loss on T1-WI out-of-phase CS sequence confirming the absence of intracytoplasmic lipid content, as well as showed heterogenous enhancement on T1-WI FS post-contrast DCE sequence according to degrees of degeneration.

In our series, the results of radionuclide imaging studies showed that in typical pheos MIBG concentration was observed in the majority (75\%) of cases as focal increased uptake allowing tumor characterization and diagnosis. However, in the two remaining cases the result of MIBG scan was false negative since tracer uptake was not observed in the tumor masses of which one was necrotic and the other of small size. These latter findings are not surprising since false negative MIBG cases may occur [7,23]. FDG scan was available only in two histologically proven large $(>5 \mathrm{~cm})$ pheos in which was performed for the clinical suspicion of malignancy; in these lesions FDG was heterogeneously increased supporting the solid tumor structure. On the other hand, the results of nuclear medicine imaging scans in atypical pheos were peculiar for tumor characterization. In particular, in these lesions the results of MRI were not diagnostic for pheo since the specific imaging criteria suggestive for this tumor-type were not present. Conversely, the majority (78\%) 
of these tumors were cystic (totally, predominantly or partially) or hemorrhagic on MRI. In these atypical pheos the concentration of the used radiotracers, both of MIBG and/or FDG, was able to characterize the residual solid tissue or the peripheral rim of these lesions allowing tumor diagnosis. This finding occurred in four lesions (one totally cystic, one predominantly cystic, one partially cystic and one hemorrhagic) using MIBG, even though in the remaining lesion no abnormal residual tracer uptake was found. Similarly, this finding occurred in eight lesions (two totally cystic, two predominantly cystic, two partially cystic and two hemorrhagic) using FDG. However, according to the specific mechanisms of MIBG and FDG tissue concentration, residual MIBG uptake allows the characterization and tumor diagnosis of pheos, while residual FDG accumulation generically reflects the presence of viable solid component of such tumor lesions. Similar findings have been previously reported either with iodine-123 MIBG single photon emission tomography (SPECT) integrated with CT [15-17,21] or with FDG hybrid imaging [13]. Therefore, according to our experience the radionuclide imaging features of such atypical pheos should be rationalized in clinical practice. In particular, when a large cystic adrenal mass may be suspected for pheo, imaging characterization is required. For this purpose, MIBG should be preferred to FDG as radiotracer for nuclear scanning. In this regard, iodine-123 represents an alternative to iodine-131 to obtain radionuclide tomographic acquisition for better comparison with MRI images [24].

To date, several limits of our study need to be listed. The first limitation consists of the retrospective type and limited number of our patient sample. The second issue that may damage the systematic design of our investigation is the lack of a homogeneous availability of radionuclide studies. Moreover, MIBG scintigraphy was acquired using iodine-131 and planar imaging, while MRI and FDG hybrid scans used tomographic acquisition; thus, the technical imaging correlation of MIBG scans versus MRI and FDG slices may limited. Finally, histologically proof of pheo was not available in one patient with typical non-hypersecreting pheo in which the result of MIBG scintigraphy was considered as diagnostic criterion for this tumor type.

\section{Conclusions}

The imaging characterization of atypical pheos represents a diagnostic challenge. A non-invasive precise pre-operative discovery is required to avoid the use of biopsies and to plan an appropriate treatment strategy. For this purpose, radionuclide imaging together with laboratory assessment are recommended to characterize such adrenal tumors. In particular, tumor accumulation of MIBG and/or FDG in the residual solid tissue or in the peripheral tumor rim is able to classify these lesions as not simple cysts, as occurred in the majority of cases of our study. In detail, the presence of also only partial or residual MIBG uptake in the lesion allows the tumor diagnosis of pheos, while the presence of also only partial or residual FDG uptake generically reflects the presence of viable solid tissue of such cystic tumors. Therefore, a cystic or hemorrhagic adrenal mass may represent an atypical pheo; diagnostic pitfalls in imaging interpretation may occur in such cystic tumor lesions.

Author Contributions: Conceptualization, S.M. and R.G.; methodology, R.G. and L.A.; software, E.N.; validation, S.M. and M.S.; formal analysis L.B., G.A.; investigation R.M.; resources, C.S.; data curation V.R. and R.G.; writing-original draft preparation, S.M. and R.G.; writing-review and editing S.M., R.G., M.S.; visualization, C.M. and E.G.; supervision, M.K. All authors have read and agreed to the published version of the manuscript.

Funding: This research received no external funding.

Institutional Review Board Statement: Institutional Review Board Statement: The study was conducted according to the guidelines of the Declaration of Helsinki, and approved by the Institutional Review Board of IRCCS SDN, Naples, Italy (protocol code 10/17).

Informed Consent Statement: The need of informed consent was waived by the IRB.

Conflicts of Interest: The authors declare no conflict of interest. 


\section{References}

1. Lattin, G.E.; Sturgill, E.D.; Tujo, C.A.; Marko, J.; Sanchez-Maldonado, K.W.; Craig, W.D.; Lack, E.E. From the radiologic pathology archives: Adrenal tumors and tumor-like conditions in the adult: Radiologic-pathologic correlation. Radiographics 2014, 34, 805-829. [CrossRef]

2. $\quad$ Blake, M.A.; Kalra, M.K.; Maher, M.M.; Sahani, D.V.; Sweeney, A.T.; Mueller, P.R.; Hahn, P.F.; Boland, G.W. Pheochromocytoma: An imaging chameleon. Radiographics 2004, 24 (Suppl. 1), S87-S99. [CrossRef]

3. Lenders, J.W.M.; Duh, Q.-Y.; Eisenhofer, G.; Gimenez-Roqueplo, A.-P.; Grebe, S.K.G.; Murad, M.H.; Naruse, M.; Pacak, K.; Young, W.F., Jr.; Endocrine Society. Pheochromocytoma and paraganglioma: An endocrine society clinical practice guideline. J Clin. Endocrinol. Metab. 2014, 99, 1915-1942. [CrossRef]

4. Maurea, S.; Cuocolo, A.; Imbriaco, M.; Pellegrino, T.; Fusari, M.; Cuocolo, R.; Liuzzi, R.; Salvatore, M. Imaging characterization of benign and malignant pheochromocytoma or paraganglioma: Comparison between MIBG uptake and MR signal intensity ratio. Ann. Nucl. Med. 2012, 26, 670-675. [CrossRef]

5. Maurea, S.; Mainenti, P.P.; Romeo, V.; Mollica, C.; Salvatore, M. Nuclear imaging to characterize adrenal tumors: Comparison with MRI. World J. Radiol. 2014, 6, 493-501. [CrossRef] [PubMed]

6. Taïeb, D.; Sebag, F.; Barlier, A.; Tessonnier, L.; Palazzo, F.F.; Morange, I.; Niccoli-Sire, P.; Fakhry, N.; De Micco, C.; Cammilleri, S.; et al. 18F-FDG avidity of pheochromocytomas and paragangliomas: A new molecular imaging signature? J. Nucl. Med. 2009, 50, 711-717. [CrossRef]

7. Taïeb, D.; Hicks, R.J.; Hindié, E.; Guillet, B.A.; Avram, A.; Ghedini, P.; Timmers, H.J.; Scott, A.T.; Elojeimy, S.; Rubello, D.; et al. European Association of Nuclear Medicine Practice Guideline/Society of Nuclear Medicine and Molecular Imaging Procedure Standard 2019 for radionuclide imaging of phaeochromocytoma and paraganglioma. Eur. J. Nucl. Med. Mol. Imaging 2019, 46, 2112-2137. [CrossRef] [PubMed]

8. Lastoria, S.; Maurea, S.; Vergara, E.; Acampa, W.; Varrella, P.; Klain, M.; Muto, P.; Bernardy, J.D.; Salvatore, M. Comparison of labeled MIBG and somatostatin analogs in imaging neuroendocrine tumors. Q. J. Nucl. Med. 1995, 39 (Suppl. 1), $145-149$.

9. Maurea, S.; Lastoria, S.; Caracò, C.; Klain, M.; Varrella, P.; Acampa, W.; Muto, P.; Salvatore, M. The role of radiolabeled somatostatin analogs in adrenal imaging. Nucl. Med. Biol. 1996, 23, 677-680. [CrossRef]

10. Patel, H.V.; Srivastava, A.; Becker, M.D.; Beninato, T.; Laird, A.M.; Singer, E.A. From Diagnosis to Therapy-PET Imaging for Pheochromocytomas and Paragangliomas. Curr. Urol. Rep. 2021, 22, 2. [CrossRef]

11. Jacques, A.E.T.; Sahdev, A.; Sandrasagara, M.; Goldstein, R.; Berney, D.; Rockall, A.G.; Chew, S.; Reznek, R.H. Adrenal phaeochromocytoma: Correlation of MRI appearances with histology and function. Eur. Radiol. 2008, 18, 2885-2892. [CrossRef] [PubMed]

12. Blake, M.A.; Krishnamoorthy, S.K.; Boland, G.W.; Sweeney, A.T.; Pitman, M.B.; Harisinghani, M.; Mueller, P.R.; Hahn, P.F. Low-density pheochromocytoma on CT: A mimicker of adrenal adenoma. AJR Am. J. Roentgenol. 2003, 181, 1663-1668. [CrossRef] [PubMed]

13. Galatola, R.; Romeo, V.; Simeoli, C.; Guadagno, E.; De Rosa, I.; Basso, L.; Mainolfi, C.; Klain, M.; Nicolai, E.; Colao, A.; et al. Characterization with hybrid imaging of cystic pheochromocytomas: Correlation with pathology. Quant. Imaging Med. Surg. 2021, 11, 862-869. [CrossRef] [PubMed]

14. Leung, K.; Stamm, M.; Raja, A.; Low, G. Pheochromocytoma: The range of appearances on ultrasound, CT, MRI, and functional imaging. AJR Am. J. Roentgenol. 2013, 200, 370-378. [CrossRef]

15. Raja, A.; Leung, K.; Stamm, M.; Girgis, S.; Low, G. Multimodality imaging findings of pheochromocytoma with associated clinical and biochemical features in 53 patients with histologically confirmed tumors. AJR Am. J. Roentgenol. 2013, 201, 825-833. [CrossRef]

16. Takarabe, D.; Takahashi, Y.; Tsujimoto, T.; Noto, H.; Kishimoto, M.; Minowada, S.; Noda, M. Cystic Pheochromocytoma Discovered as an Adrenal Incidentaloma. J. Med. Cases 2013, 0034, 753-757. [CrossRef]

17. Cajipe, K.M.; Gonzalez, G.; Kaushik, D. Giant cystic pheochromocytoma. BMJ Case Rep. 2017, 2017, bcr2017222264. [CrossRef]

18. Andreoni, C.; Krebs, R.K.; Bruna, P.C.; Goldman, S.M.; Kater, C.E.; Alves, M.T.D.S.; Ortiz, V. Cystic phaeochromocytoma is a distinctive subgroup with special clinical, imaging and histological features that might mislead the diagnosis. BJU Int. 2008, 101, 345-350. [CrossRef]

19. Lee, T.H.; Slywotzky, C.M.; Lavelle, M.T.; Garcia, R.A. Cystic pheochromocytoma. Radiographics 2002, 22, 935-940. [CrossRef]

20. Čtvrtlík, F.; Koranda, P.; Schovánek, J.; Škarda, J.; Hartmann, I.; Tüdös, Z. Current diagnostic imaging of pheochromocytomas and implications for therapeutic strategy. Exp. Ther. Med. 2018, 15, 3151-3160. [CrossRef]

21. Costa, S.R.P.; Cabral, N.M.; Abhrão, A.T.; Da Costa, R.B.; Da Silva, L.M.; Lupinacci, R.A. Giant cystic malignant pheochromocytoma invading right hepatic lobe: Report on two cases. Sao Paulo Med. J. 2008, 126, 229-231. [CrossRef] [PubMed]

22. Schieda, N.; Alrashed, A.; Flood, T.A.; Samji, K.; Shabana, W.; McInnes, M. Comparison of Quantitative MRI and CT Washout Analysis for Differentiation of Adrenal Pheochromocytoma From Adrenal Adenoma. AJR Am. J. Roentgenol. 2016, 206, 1141-1148. [CrossRef] [PubMed] 
23. Dell'Aversana, S.; Romeo, V.; Assante, R.; Klain, M.; Maurea, S. False iodine-131 MIBG scintigraphy findings in adrenal tumors: Correlation with MRI imaging. Clin. Transl. Imaging 2021, 9, 109-115. [CrossRef]

24. Wiseman, G.A.; Pacak, K.; O’Dorisio, M.S.; Neumann, D.R.; Waxman, A.D.; Mankoff, D.A.; Heiba, S.I.; Serafini, A.N.; Tumeh, S.S.; Khutoryansky, N.; et al. Usefulness of 123I-MIBG scintigraphy in the evaluation of patients with known or suspected primary or metastatic pheochromocytoma or paraganglioma: Results from a prospective multicenter trial. J. Nucl. Med. 2009, 50, 1448-1454. [CrossRef] [PubMed] 